\title{
What should students learn in the digital world?
}

\section{Harth, Thilo ${ }^{a}$ and Dellmann, Frank}

${ }^{\mathrm{a}}$ Wandelwerk - Centre of Quality Development, Muenster University of Applied Sciences, Germany, ${ }^{b}$ Vice president for Teaching and International Affairs, Muenster University of Applied Sciences, Germany

\begin{abstract}
The rapid changes in the working environment and society as a whole as a result of digitalisation demands a new and changed competence profile. Specialist requirements are changing, and extracurricular requirements are of growing significance. Curriculum development at higher education institutions should take note of this change in order to ensure that higher education graduates are ready for professional life, and to reinforce personal development in the digital world. What should students learn in the digital world? This question invites us to consider further, from a digital perspective, the competency orientation in higher education. This article will demonstrate approaches to competency-oriented curriculum development, to consider the digital transformation in skills profiles and to render this process more dynamic. This article is based on experiences at a higher education institution that has encountered the challenges of digital transformation.
\end{abstract}

Keywords: competency orientation, digitalisation, curriculum development, learning for employment 


\section{Digital transformation - transformation of curricula?}

"Digitalisation is the transformation of society and the professional world as a result of current progress in information and communication technology" (Kreulich \& Dellmann 2016, p. 11). Many times digitalisation is considered in teaching by using digital teaching methods. Often the choice of the medium comes first, followed by looking for the appropriate didactic concept. In our framework we start with the didactic concept beginning with the question how necessary competences are influenced by digitalisation.

The global data pool has exploded as a result of digitalisation and networking. In order for a person to properly evaluate and utilise this immense volume of data, they must first understand it. In the professional, industrial world (Industry 4.0), this does not simply refer to, say, the ability to understand how devices and facilities operate, but also the ability to select and apply suitable sensor and measurement technology in order to access the useful data. For example, the digital flood of data increasingly requires all members of our society to be able to select and filter data in an appropriate manner. The current debate regarding "fake news" (Shellenbarger 2016) is a clear representation of this. Accordingly, our increasingly digital society and professional world also demand new and transformed competence profiles, including in the curricula of courses at higher education institutions. This is especially true when one considers that current and prospective students possess increasingly different skills profiles. "The group of so-called "digital natives" is appearing, with new and different expectations of a higher education institution" (Kreulich \& Dellmann 2016, p. 10).

While the professional world and society as a whole have seen rapid transformation as a result of digitalisation and networking, the curriculum development at higher education institutions has instead been decidedly sluggish (Jenert 2016, p. 122). Alongside the requirement for new and transformed competence profiles in courses of study, the process of curriculum development should also be transformed in order to make courses' requirements more up-to-date and in order to (better) meet the needs of future generations of students. As a potential answer to this, this article will present a strategy in three phases that we are currently trialling at our higher education institution: taking competency orientation seriously, reconsidering competency orientation from a digital perspective, and making curriculum development more agile. 


\section{Taking competency orientation seriously}

In the European Higher Education Area, the concept of competency orientation in study and teaching is - formally, at least - extensively considered and implemented (Schaper 2012, p. 6). "The competency-oriented design of courses of study, classes and testing is a central requirement of the European Academic Reforms" (HRK Nexus, n. y.). Newlydeveloped courses of study must be designed in a competency-oriented manner, and the various levels of higher education qualification defined using indicative skills targets.

However, "only in a few cases has it been possible to adequately implement the didactic requirements associated with competency orientation" (Schaper 2012, p. 6). That is hardly surprising, and an orientation towards 'learning outcomes' and the accompanying focus on skills acquisition by students necessitates a demanding change in teaching and learning culture (a shift from teaching to learning). The teacher imparting knowledge is no longer at the forefront, and this is instead replaced by the acquisition or further development of competencies by the students themselves: higher education graduates should be able to exhibit effective and adequate processes to solve both everyday and professional problems and situations. They should be able to translate knowledge into actions (and thereby avoid inert knowledge), which thus constitutes increased requirements on the didactic and methodical structure of teaching and examinations in order to stimulate, support and accompany the development of the students' skills.

In order to meet the demands on competency orientation in a practical manner and produce a coherent blend of learning outcomes, teaching and learning processes and different forms of examination, the concept of Constructive Alignment (Biggs \& Tang 2011) has gained currency in higher education institutions. Based on the formulation of competencies as a result of the student learning process (learning outcomes), adequate teaching and learning formats and forms of testing can be derived. This process is highly demanding, as teachers with differing methods must first agree on common learning outcomes, realise the value of extracurricular skills, and subsequently draw conclusions for the structure of their teaching and testing - something which does not simply mean abandoning the "beaten track" and additional work.

To support this, so-called 'curriculum workshops' have been established. They are a communication forum in which a project group - ideally composed of all parties including course leaders, academic deans, teachers, student and external representatives, amongst others - comes together and appreciates the development of courses of study as a joint effort (Harth 2015, p. 39). Integrating external moderation, consultancy, assistance and above all didactic stimulation - by the higher education institution's internal Centre for Quality Development or similar - can significantly support this process. The external expertise can also include an open, methodical approach (e.g. the design-thinking method), 
to support in differentiating between various competence levels or to reflect on interim results.

Case examples from actual course development in curriculum workshops show that this method can lead to agreement on common learning outcomes in a course of study, and can lead to recognition of the considerable significance of extracurricular skills. Harth et. al. (2017) reports the successful operationalisation of the qualification goal of "building, operating and dismantling life-cycle oriented structures" in a curriculum-workshop with structural engineers. Academic skills and interdisciplinary competences were prioritised in the discourse. "In this process, for example, all participants were particularly aware of the considerable significance of target-group specific communication skills regarding local politicians, administration, legal professionals and developers. These experiences and others like them led the participants to the 'aha moment', which makes the content of this arduous formulation process worthwhile, qualitatively develops the course of studies, allows teaching to demonstrate the direct and methodical application of theory, and does not simply meet formal requirements in the form of a "formulaic prose"' (Harth et.al. 2017, p. 18). However, taking competency orientation seriously not only means a logical focus on learning outcomes, but also taking into consideration the students' various competence levels on beginning the course of study. In both directions, it is worthwhile considering the concept of competency orientation and the effects of the digitalisation.

\section{Rethinking (digital) competency orientation}

The changed skills amongst current generations of students and school pupils on starting a course of study is particularly prevalent in the USA. A proponent of this idea is author Marc Prensky, who was the first to introduce the term "digital natives" to the debate, and who currently writes about "extended minds" in relation to young people's easy access to smartphones. "These new devices allow kids not only to take in information (as they could with reading) and create reports (as they could writing), but to combine, analyze, and manipulate information in very new ways" (Prensky 2016, p. 14). It is perfectly clear that the availability and reach of digital media now enables access to new bodies of knowledge, other forms of communication and above all a completely different communication behaviour. Competency orientation at higher education institutions should consider the influence of the digital world not only with regard to communication and (digital) media skills and in connection with critical and sensitive handling of data, but should instead take all spheres of competence into consideration. In an initial step, Kreulich \& Dellmann have highlighted three characteristic displacements as a result of digitalisation in each of the extracurricular skills areas of methodical, personal and social competences (Kreulich \& Dellmann 2016, p. 21-52). For example, in the context of a higher education institution, the decision-making ability derived from the greater freedom of choice in the world of digital consumerism, and the generally free-of-charge take-back obligation in the case of a wrong 
decision, translate into students' behaviour when making decisions on compulsory modules or in examinations. The binding nature of decisions and their consequences - similar in nature to those in future professional life - must often be learnt from scratch (ibid., p. 28).

As a principle, for each course of study it is useful to identify skill areas that are reducing in significance as such activities will be better conducted digitally in future. Above all, this concerns repetitive routine work. On the other hand, focus should be given to skill areas that are of greater significance due to the influence of digitalisation and the resulting requirements of society and the professional world. Surveys show that personal and social competencies are of increased significance as a result of digitalisation (Stifterverband 2016). The Director of the Centre for E-Business at the Massachusetts Institute of Technology (MIT) emphasised the need to promote teamwork, creativity and social skills in particular (Brynjolfsson 2016).

The joint research of higher education teachers from a range of disciplines into the influence of digitalisation on skills changes is the subject of workshops both within and beyond our institution. These workshops firstly consider the obvious academic changes and the evident shift in terms of communication skills towards multitasking abilities, or the ability to deal with the current overload of data and information (ability to focus). In addition, however, they also consider the relevant changes to extracurricular skills due to the influence of digitalisation, which only become evident on closer inspection. Then, by way of example, specialist courses particularly affected by the digital transformation (logistics, building automation) are considered. At the same time, digital teaching formats (e.g. a health skills lab, live classroom for social work courses) are examined more closely for their potential in terms of skills acquisition in the digital world. The aims of this collegial exchange are:

- to make teachers more aware of the transformation effected by digitalisation,

- to make good practice transparent in all areas of higher education,

- to identify further training needs,

- to generate conclusions to apply to curriculum development and the didactic and methodical structure of teaching, and

- to adapt higher education infrastructure (e.g. library facilities, lecture hall design) to serve changed competence requirements.

Three central dimensions can be derived from this discursive process: 


\subsection{New competence areas}

When considering the effects of digitalisation on students' academic profiles, the change from specific to generalist competences has been particularly evident to date. This can be illustrated with an example from our university: In the field of building technology in architecture studies, the ability to precisely calculate heating requirements or correctly calculate radiator dimensions will be less important, as computer programmes will soon be able to calculate these figures quickly, precisely and easily by entering known parameters. Instead, prospective architects must demonstrate themselves to be generalists, with an overarching understanding of energy concepts. In order to work professionally as an architect, the ability to bring together numerous influencing factors (such as light, air and warmth) to create an integrated energy analysis is increasingly important. Digital tools such as databases or computer simulations can again prove helpful in developing this generalist skills profile.

Integrating digital media into teaching provides increased awareness of transfer competence. Digital simulations of professional situations must be reviewed in hindsight, to examine the extent to which they are realistic. For example, students in the nursing care skills lab at our university work with an interactive dummy, but without the environmental conditions often encountered in practice such as overcrowded rooms and insufficient staffing. The transfer of skills into reality must not be forgotten in the learning process. Both of these examples can be used to illustrate that the skills profile in module descriptions should be heightened as a result of digitalisation, and that consequent changes are required in the teaching and testing process. This also applies for competency shifts.

\subsection{Altered skills profiles}

In the digital world, the ability to work in a team is shifting towards inter-culturally sensitive, written collaboration skills from remote locations. At the same time, problem solving abilities are regularly shifting towards intelligent usage of the various team resources in the global, virtual space. Problem solving processes in higher education learning should therefore be developed collaboratively, and analogous to the virtual team process. The potential ability to digitally store the learning process presents a particular opportunity. Students can, for example, be filmed in simulations of professional situations or during laboratory experiments, in order to collectively analyse and reflect upon the learning process, rather than simply regarding the learning outcome as the result of summative testing. The skills acquisition process therefore becomes (more) transparent, and presents the opportunity to practice analytical and reflective skills. The final issue in terms of a skills shift is underlined by responsibility when dealing with digital data, with the aim of digital self-determination. How are private and public spheres shifting, and how can we set limits on these? How responsibly do I act in the digital world? 


\subsection{Relocation of skills}

Digitalisation often entails acceleration processes and (all too) immediate solutions. For example, students in the fields of design, architecture or engineering turn all too quickly to a wide range of computer programmes for planning, designing and construction. The programme then defines the operational framework. However, the structured actions in the planning, construction or designing processes end up overlapping, or often turn out to be too short. The response to this deficit is the conscious deceleration of the learning process, a return to an analogue space and a focus on basic competencies. Before the digital tools are applied, students should be taught skills on how to generate ideas with a pencil and paper, skills for evaluating, estimating and calculating key construction parameters should be strengthened, and focus should be placed on basic research when planning. In terms of curriculum development, when designing a module, care should be taken to ensure that sufficient time is designated for developing basic skills.

\section{Making curriculum development more agile}

This insight into new, altered and relocated competency profiles emphasises the need to rethink higher education curricula in the digitalised world. To determine what students should learn today, skills changes must be identified, these changes anchored in modules and actively integrated into teaching and testing. Moreover, making higher education curricula more practically relevant to the digital world is a more pressing issue than ever. A look at vocational training can be helpful in this regard. The aims of achieving professional skills are manifested in the organisation of professional teaching in learning fields rather than in teaching subjects. These learning fields are oriented towards professional realities (Riedl 2011). In the learning field for mechanics, for example, there are 60 teaching hours dedicated to physically overhauling a gearbox, as opposed to purely academic content such as gearbox technology, materials science or manufacturing technology. In this theoretical concept, the transformational dynamic of digitalisation can be followed and considered (even if this is generally not integrated or attempted in school practice). In educational discourse in the USA, the new digital possibilities have led to discussions of the need to focus on "real-world problems" in education processes (Prensky 2016, p. 3), and of "educating a generation of solutionaries" (Weil 2016).

At our higher education institution, enhancing the practical relevance of teaching is also an attempt to make curriculum development more agile. Based on the agile Scrum software development method (e.g. Goll \& Hommel 2015), an agile curriculum development process was created at our Institute for Technical Business Management. In their 'Digitalisation' module, future business administrators are given the task of conducting interviews with different kinds of Managers in order to identify current and specific skills requirements in their professional field. The results of the interviews (supplemented data from with further 
research) are compared with the course profile. The purpose of this is not only to make students aware of current skills requirements, but also to react appropriately by modifying the module during the course of study. This pilot scheme was supported and recognised by the Association for the Promotion of Humanities and Sciences in Germany in funding scheme Curriculum 4.0 as one of nine projects across Germany in 2016.

\section{Summary}

The competency orientation and the associated outcome orientation makes higher education institutions aware of what students should learn. In our view, this outcome orientation must be further considered in the digital world. Due to the influence of digitalisation and networking, skills profiles are undergoing such fundamental transformations that curriculum development should react more quickly. This does not necessarily require an agile curriculum. Nonetheless, a central strategic task for higher education institutions is defined herein. Perhaps the insight into our strategic process can act as stimulation for other higher education institutions. In our strategy, we began with curriculum development, which evidently must - and which will - be continued with systematic adaptation of teaching and studies and of the infrastructural framework.

\section{References}

Biggs, J. \& Tang, C. (2011). Teaching for Quality Learning at University. What the Student Does. 4th Edition. Maidenhead.

Brynjolfsson, E. (2016). "Es läuft nicht mehr wie früher”, in: Die Zeit no. 15, 31.03.2016.

Goll, J. \& D. Hommel (2015): Mit Scrum zum gewünschten System. Wiesbaden

Harth, T. (2015). 100 Begriffe für die Hochschullehre, in: Harth/Boentert (Eds.), Werkstattberichte des Wandelwerks Vol. 7, Münster.

Harth, T., Pernhorst, C., Krämer, J. u. K. Hombach (2017). Kompetenzorientierung mit Curriculum-Werkstätten. in: Neues Handbuch Hochschullehre, Book 79 2017, p. 1-18

HRK Nexus (n.y.). Kompetenzorientierung; available online at: http://www.hrknexus.de/themen/studienqualitaet/kompetenzorientierung/, retrieved 22.01.2017

Jenert, T. (2016). Von der Curriculum zur Studienprogrammentwicklung: Argumente für eine Perspektivenerweiterung. In: Brahm, T., T. Jenert and D. Euler (Eds.) (2016): Pädagogische Hochschulentwicklung. Wiesbaden, p. 119-132.

Kreulich, K. \& Dellmann, F. et al. (2016). Digitalisierung - Strategische Entwicklung einer kompetenzorientierten Lehre für die digitale Gesellschaft und Arbeitswelt, Berlin

Prensky, M. (2016). Education To Better Their World, New York.

Riedl, A. (2011). Didaktik der beruflichen Bildung. Stuttgart.

Schaper, N. (2012). Fachgutachten zur Kompetenzorientierung in Studium und Lehre, produced for the HRK by N. Schaper, assisted by O. Reis, J. Wildt, E. Horvath and E. Bender, August 2012, https://www.hrk-nexus.de/material/links/kompetenzorientierung retrieved 28.01.2017 
Shellenbarger, S. (21 November 2016). "Most Students Don't Know When News Is Fake, Stanford Study Finds", The Wall Street Journal, retrieved 28.01.2017

Stifterverband für die Deutsche Wissenschaft (2016). Hochschulbildung für die Arbeitswelt 4.0 - Hochschul-Bildungs-Report 2020, Jahresbericht 2016, Essen.

Weil, Z. (2016). The World Becomes What We Teach. New York. 